\title{
INFLUENCES OF PARENTS AND PEERS ON ADOLESCENT SMOKING INITIATION: FINDINGS FROM A LONGITUDINAL STUDY IN KOTA TINGGI DISTRICT, JOHOR, MALAYSIA
}

\author{
Lim Kuang Hock ${ }^{1}$, Lim Hui $\mathrm{Li}^{2}$, Sumarni Mohd Ghazali ${ }^{1}$, Cheong Yoon Ling ${ }^{1}$,Kee Chee Cheong ${ }^{3}$,Heng Pei \\ $\mathrm{Pei}^{1}$, Teh Chien Huey ${ }^{1}$, Tan Cia Vei $^{1}$, Mohd Hazilas Mat Hashim ${ }^{1}$, Cheah Yong Kang ${ }^{4}$ and Lim Jia Hui ${ }^{5}$ \\ ${ }^{1}$ Institute for Medical Research, National Institutes of Health, Ministry of Health Malaysia, Jalan Pahang, \\ 50588 Kuala Lumpur \\ ${ }^{2}$ Hospital Sultan Ismail, Ministry of Health Malaysia, Taman Mount Austin, 81100, Johor Bahru, Johor. \\ ${ }^{3}$ Sector for Biostatistics and Data Depository, National Institutes of Health, Ministry of Health Malaysia, \\ Setia Alam, 40170 Shah Alam, Selangor \\ ${ }^{4}$ School of Economics, Finance and Banking, College of Business, Universiti Utara Malaysia, 06010 \\ UUM Sintok, Kedah Darul Aman \\ ${ }^{5}$ Hospital Putrajaya,Ministry of Health Malaysia,Presint 7, 62250 Putrajaya, Wilayah Persekutuan \\ Putrajaya.
}

Corresponding author:Lim Kuang Hock

Email: limkh@moh.gov.my

\begin{abstract}
Studies have shown that parents and peers are among the dominant factors that contribute to smoking initiation among non-smoking adolescents. The paucity of this information in Malaysia warrants a longitudinal study to determine the actual factors associated smoking initiation. The study aims to address the gaps in our knowledge on the factors that associated with smoking initiation among non-smoking school-going adolescents. We carried out a longitudinal study among non-smoking secondary school-going adolescents in Kota Tinggi district, Johor. A representative sample of 1682 was selected via multi-stage sampling and respondents were followed-up for a period of one year. A pre-validated questionnaire was used to collect data from the selected respondents and multivariable logistic regression was employed to determine the factors associated with smoking initiation among non-smoking school-going adolescents. Approximately 1 in 10 non-smoking school-going adolescents-initiated smoking at the end of follow-up. Having peers and a father who smokes were significantly associated with smoking in univariate analysis, similarly relationship was also observed in multivariable analysis between parents who smoked with smoking initiation after the effect of other independent variables were controlled (Adjusted relative risk: 1.81, 95\% Cl 1.06-2.95). The study revealed that parental influence was more dominant than peer influence with regards to smoking initiation. Therefore, intervention programmes should involve parents/guardians to enhance their chances of success and reduce the incidence of smoking among non-smoking school-going adolescents.
\end{abstract}

Keywords: longitudinal study, non-smoking adolescents parental influence, peer influence, smoking initiation

\section{INTRODUCTION}

The habit of smoking is commonly learnt and initiated in adolescence. Among daily smokers, over $85 \%$ tried their first cigarette by the age of 18 and almost $65 \%$ began smoking regularly upon that age 1 . The Malaysian National Health and Morbidity Survey in 2015 reported that $70 \%$ of adult smokers started smoking at 18 years old and the mean (SE) age of initiation was 16.52 (s.d. 0.08 ) years ${ }^{2}$. Majority of the youths who initiated smoking tend to become addicted after taking a few cigarettes ${ }^{3,4}$ while individuals who did not smoke during adolescence were less likely to smoke when attained adulthood ${ }^{4}$. The younger a person started smoking, the higher the risk for exposure to smoking related diseases (CVD and multiple types of cancer) with lesser likelihood to quit smoking ${ }^{4-6}$. Thus, reducing the incidence of adolescent smoking initiation is one of the government's long-term strategies to reduce health problems related to smoking among Malaysians ${ }^{7}$.

The Social Learning Theory posits that the process of acquiring certain behaviours, including smoking is achieved through social modelling, in which the perceived behaviour of others acts as a central source of learning ${ }^{8,9}$. The most effective learning process occurs in the presence of similarity between an individual and their role model, comprising of their peers and parents.In regards to this, the importance of parental modelling on adolescents' smoking behaviour is established ${ }^{10-13}$. For instance, LeonardiBee, Jere, and Britton ${ }^{14}$ found an elevated risk of smoking uptake in childhood and adolescence when at least one parent smoked. Similarly, an adolescent with peers who smoked was more likely to initiate smoking ${ }^{14-17}$. The researcher postulated that adolescence was the identity-searching time period, with them referring to and emulating their peers' behaviour, including smoking ${ }^{18-19}$. 
In Malaysia, numerous studies depicting the smoking habits of adolescents had been carried out in the past three decades, with the majority ones reporting significant association between having peers who smoked and their own smoking status $^{16-18,20,21}$. Noted there was an exclusive research which described a significant interrelation between father's smoking status and adolescents' ones ${ }^{22}$. Therefore, this paper aims to delineate the role of peer and parental factors in influencing smoking among non-smoking adolescents using a longitudinal study conducted among secondary school students in Kota Tinggi , Johor (The locality was chosen in view of its unique locality which consisted of urban, rural and land settlement areas). The comprehension of relationship between factor(s) (parental or peer or both) and adolescent smoking habit will aid in reducing the smoking initiation incidence among youths, consequently posing a long-term impact on the prevalence of smoking in the Malaysian population.

\section{METHODS}

The data was derived from a longitudinal study among secondary school going adolescents in Kota Tinggi District, Johor, Malaysia. The study utilised multistage, proportionate to size, cluster sampling to select a representative sample of form one (13 years), form two (14 years) and form four students (16 years) secondary school students in Kota Tinggi, Johor. Non-smoking students were assigned to unique identification (ID) at baseline and were followed-up after one year. A sample size of 2,700 was calculated based on the smoking incidence rate of $3 \%$ for form 1 and 2 students, and $6 \%$ for form 4 students. The sample size taken into the consideration of $30 \%$ of non-response rate and $30 \%$ for exclusion of smokers. The study was approved by the Ministry of Education, State Education Department and ethical clearance was obtained from the Medical Research and Ethics Committee, Ministry of Health, Malaysia.

A validated questionnaire adopted from Hanjeet et al was used to collect data at baseline and upon follow-up ${ }^{2}$. Respondents who reported at least one-time smoking in the past 30 days during baseline study were excluded from the follow-up study. The dependent variable was smoking status at follow-up (Smoked at least once in past 30 days was categorised as current smoking). The independent variables were "Number of best friends who smoke"(categorised as 0, 1-5), and "parent(s) smoking status (Yes/No). Confounding variables, identified based on literature review and included in the analysis comprised of social and demographic characteristics (gender, form/grade, school locality), elderly brother smoking, perceived social acceptance and parents/guardian toward their smoking behaviour (Likert type scale 1-7), intention to smoke in future (yes/no), school area, pros and cons of smoking (measured by Decision balance Inventorymeasured in Likert scale).

\section{Measures}

Only respondents who consented in written form by their parents/guardians were allowed to participate in the study. Besides that, the participants were to sign on the questionnaires to indicate their willingness to participate and were assured of their anonymity. The similar measures /approaches were used in both baseline and follow-up .Questionnaires were self-administered by the students at school premises without the presence of teachers nor school staffs. Prior to data collection, trained research team members briefed the respondents on the study objectives and study procedures. They were informed that their participations were voluntary and were given assurance that the data were solely for research purposes. At the same time, they were also offered explanation for all of the items in the questionnaires. Respondents who faced difficulties understanding any of the items were assisted by the research team members. Some respondents will be selected to undergo a test to determine exhaled carbon monoxide concentration for verification of smoking status after the data collection session (The approach was taken to minimise the disturbance to the respondents in their study at school). The study protocol was approved by the Malaysian Ministry of Education and the Medical Research and Ethical Committee, Ministry of Health, Malaysia.

\section{Data management and data analysis}

Baseline and follow-up data were merged based on the unique ID and cleaned prior to analysis. Descriptive analysis was performed for sociodemographic variables. Relationship between number of peers who smoked and father's smoking status with the dependent variable smoking initiation was examined using Pearson chi-square, whilst other confounding variable (perceived social and parents/guardian acceptance of their smoking behaviour, pros and cons of smoking, gender, school area, age, intention to smoke in the future, elder brothers smoking status) with $p$ value less than $p=0.25$ in univariate analysis was included in the multivariable binary logistic regression to adjust for confounding. Two-way interactions between the independent variables and confounding variables were assessed in the final model, and no significant interactions were detected $(p>0.05)$. The Hosmer-Lemeshow chi square $p$ value of 0.645 indicated that the final model was fit. All statistical analyses were carried out at 95\% confidence interval using SPSS version 20.

\section{RESULTS}

Out of the 1,682 non-smoking respondents at baseline, 1,246 (74.1\%) participated during follow-up session. Among the 1,246 participants, $50.1 \%$ were male with almost three quarters of 
the respondents comprised of Form 1 and 2 students and more than half of them (58.0\%) went to school in land-settlement areas (Table 1).

It was apparant from Table 2 that $12.2 \%$ nonsmoking adolescents initiated smoking after a year. The proportion of adolescents who had smoker friend/s were almost three times more prone to commence smoking compared to those without any friend who smoked $(23.2 \%$ vs $8.7 \%$, $\mathrm{P}<0.001)$. Having a father/male guardian who smoked was significantly associated with smoking initiation among non-smoking adolescents after one year $(14.1 \%$ vs $9.6 \%, p=0.023)$. Multivariable analysis revealed that adolescents with father/male guardian who smoked was $81 \%$ higher risk of initiating smoking compared to their counterparts whose fathers did not smoke (AOR 1.81, 95\% Cl 1.06-2.95, $\mathrm{p}=0.024)$. However, the association between having a friend/s who smoked with smoking initiation was insignificant (AOR 1.58, $95 \% \mathrm{Cl} 0.91-2.64, \mathrm{p}=0.115$ ) after controlling for the effects of the other independent variables.

Table 1: Social and demographic characteristic of respondents in follow-up study

\begin{tabular}{lll}
\hline Variable & $\mathbf{n}$ & $\%$ \\
\hline Gender & & 50.1 \\
Male & 624 & 49.9 \\
Female & 622 & \\
Schooling areas & & 42.0 \\
Urban \& Rural & 519 & 58.0 \\
Land settlement & 716 & \\
Form of study & & 77.6 \\
$1-2$ & 969 & 22.4 \\
\hline
\end{tabular}

Table 2: Univariable and multivariable analysis to determine relationship between smoking initiation and number of best friends and parental smoking status

\begin{tabular}{|c|c|c|c|c|c|c|c|}
\hline \multirow[b]{2}{*}{ Variable } & \multicolumn{2}{|c|}{ Smoking initiation } & \multicolumn{2}{|c|}{$\begin{array}{c}\text { Univariable } \\
\text { analysis }\end{array}$} & \multicolumn{3}{|c|}{ Multivariable analysis } \\
\hline & $\begin{array}{l}\text { Yes } \\
\mathrm{n}(\%)\end{array}$ & $\begin{array}{l}\text { No } \\
\mathrm{n}(\%)\end{array}$ & $\begin{array}{l}\text { Chi- } \\
\text { square }\end{array}$ & $P$ value & $\begin{array}{l}\text { Adjusted } \\
\text { risk } \\
\text { ratio } \\
\end{array}$ & $95 \% \mathrm{Cl}$ & $\begin{array}{c}P \\
\text { value }\end{array}$ \\
\hline \multicolumn{8}{|l|}{ Gender } \\
\hline Male & $142(21.7)$ & $511(78.3)$ & 112.38 & $<0.001$ & 6.10 & $\begin{array}{l}2.93- \\
12.95\end{array}$ & $<0.001$ \\
\hline $\begin{array}{l}\text { Female } \\
\text { Form of study }\end{array}$ & $15(2.4)$ & $617(97.6)$ & & & Ref. & & \\
\hline Form 1-2 & 139(13.9) & $860(83.1)$ & 12.4 & $<0.001$ & 1.75 & $\begin{array}{l}1.05- \\
2.93\end{array}$ & 0.02 \\
\hline $\begin{array}{l}\text { Form } 4 \\
\text { Schooling areas }\end{array}$ & $18(6.2)$ & $271(93.8)$ & & & Ref. & & \\
\hline Urban/rural & $56(10.5)$ & $479(89.5)$ & 1.90 & 0.168 & Ref. & & \\
\hline Land settlement & $96(13.0)$ & $642(87.0)$ & & & 1.08 & $\begin{array}{l}0.62- \\
1.56\end{array}$ & 0.252 \\
\hline \multicolumn{8}{|l|}{ Parent/s smoking } \\
\hline Yes & $80(14.1)$ & $488(85.9)$ & 5.20 & 0.023 & 1.81 & $\begin{array}{l}1.06- \\
2.95\end{array}$ & 0.024 \\
\hline $\begin{array}{l}\text { No } \\
\text { Elder brother } \\
\text { smoking }\end{array}$ & $51(9.6)$ & $642(87.0)$ & & & Ref. & & \\
\hline $\begin{array}{l}\text { Yes } \\
\text { No }\end{array}$ & $\begin{array}{l}58(13.0) \\
39(12.4)\end{array}$ & $\begin{array}{l}388(87.0) \\
276(87.6)\end{array}$ & 0.07 & 0.799 & & & \\
\hline
\end{tabular}


Table 2: Continue

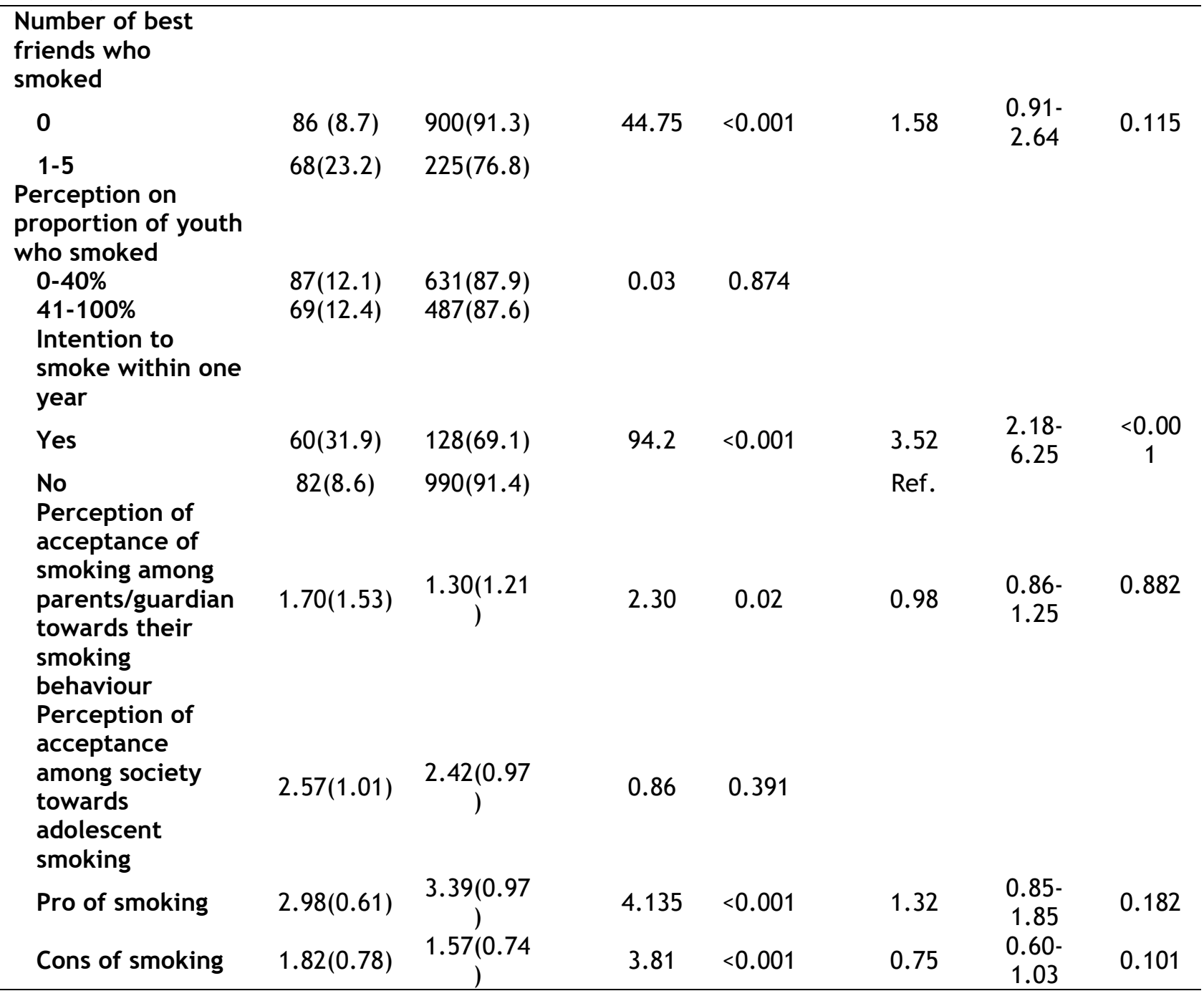

\section{DISCUSSION}

To the best of our knowledge, this study is the first to provide preliminary evidence in identifying factors leading to smoking initiation among nonsmoking school-going adolescents in Malaysia. Our finding indicates that more than $10 \%$ of nonsmoking Malaysian youth initiate smoking after a period of one year, which is higher than the $5 \%$ and $7 \%$ among two youth cohorts in Portugal reported by Victoria et al. ${ }^{13}, 24$. This may be attributed to the fact that there are dissimilarities in anti-smoking policies and methods of implementation between the two countries which contribute to the differences in smoking incidents that differ between these two studies. The higher incidence of the smoking initiation among non-smokers in this study might be due to the causality that majority of the respondents (more than $80 \%$ ) in this study are from Malay descents. It is postulated that the higher prevalence of smoking among Malays adults $(24.7 \%)^{2}$ might influence this study's respondents in the commencement of smoking behavior.

Our study depicts insignificant influence of peers on smoking initiation among school-going adolescents in contrary to a systematic review by Wellman et al., which compiled 54 longitudinal studies and reported 26 out of 28 studies to show significant causal-relationship between peer and smoking initiation among non-smoking youths ${ }^{25}$. It also contradicts with the systematic review and meta-analysis by Liu et al. , that included 75 studies of adolescents initiate smoking (1.96, 95\% $\mathrm{Cl}[1.76,2.19])^{26}$ in addition to several longitudinal studies that showed causalrelationship between peer smoking with smoking initiation among non-smoking youth ${ }^{13,}$ 27-29. The discrepancy might be caused by the variation in parenting style in between the studies, in which the parents/guardian in Kota Tinggi are possibly more caring with more attention and positive communication with their children. Therefore, this factor safeguards adolescent from unfavourable peer influence as noted in previous studies $^{30-31}$. Concomitantly, the relationship established between respondents and peers may also differ in between this study and previous studies, which in turn causing discrepancy in results. Nevertheless, this postulation needs to be investigated in depth via qualitative study. 
Our study is in congruent with several researches conducted among youth ${ }^{32-34}$. Bricker et al. who carried out a survey involving 5,520 American families revealed that youth with parents who smoked had a higher tendency to experiment with smoking and to progress to daily smoking from monthly smoking ${ }^{34}$. Similarly, Harakeh et al. reported that parents' influence on non-smoking adolescents to initiate smoking using an extension of the Theory of Planned Behavior ${ }^{11}$. In addition, May et al. concluded that for children of neversmokers, only $13 \%$ tried at least one cigarette in their lifetime, compared to 38 percent for the children of smokers ${ }^{33}$. Concurrently, only $5 \%$ of the former group reported a nicotine addiction, compared to 15 percent of the latter one. Furthermore, our results are also in consistent with the finding among representative samples of youth in Taiwan ${ }^{35}$ which documented that fathers/parents were the main role models for the development of smoking habit among children. We presume that the results in this study can be explained by the fact that parents who smoke in front of their children act as negative influence and indirectly provide the false impression that smoking is a normative behaviour among adults. Adolescents will imitate their parents' smoking behaviour in order to satisfy their desire to behave like adults. Our finding provides an extension to Bandura's Cognitive Social Theory which posits that we tend to adopt behaviours that we have learnt from observation of others, especially our role models that incorporate our parents/guardians. The evidence from this study indicates that parental smoking status contributes to smoking initiation among non-smoking adolescents, the effects of which remains even after other risk factors are being controlled. This finding among Malay male students is supported by another study in Kota Bharu, Kelantan, Malaysia whereby the odds of being current smokers was almost two-times higher among male students with father smoking compared to their counterpart without father smoking ${ }^{22}$.

Secondly, parents who smoke tend to be more liberal with regards to smoking ${ }^{17,36}$,resulting in increased likelihood to be disengaged and manifesting neglectful parenting style ( lower levels of acceptance and control with lesser tendency to convey the hazards of smoking to their children ${ }^{37}$ ), which might lead to the thinking that smoking is acceptable and permitted by their parents. In addition, smoking parents may be also aware of their lack in credibility to advise their children not to smoke as they themselves are actively doing it too ${ }^{17}$. A study by Flay et al. exhibited that parental smoking influenced adolescents' smoking onset indirectly through perceived parental approval ${ }^{38}$. Thirdly, in Asian culture, children are taught of the value of filial piety and respect for elderly in the family since young. Consequently, they are prone to be more submissive to their parents/guardians, whose parenting style are usually authoritarian, this might be another important factor in influencing adolescents, compared to their counterparts in Western countries ${ }^{17,} 35$.

\section{CONCLUSION}

This paper presented that parental smoking is deemed more impactful on adolescent smoking initiation when compared to peer smoking. Previous local studies which reported significant association between smoking behaviour and adolescents' current smoking status might be due to the rationale that smoking adolescents who are actively selecting and displaying preference to socialize with peers who smoked. However, considerably more work will need to be done to verify this hypothesis.

The findings presented here may facilitate improvements in several research directions. Firstly, the study utilised self-reported measures, thus there might be elements of social desirability bias in the questionnaire responses. Secondly, most of the constructs were measured by a single item and smoking status was not validated by biochemical measurement. In regards to that, previous studies conducted locally and abroad had reported high validity of self-reported smoking when respondents' confidentiality were guaranteed ${ }^{39}$. Thirdly, as in any longitudinal research, this study had a $26 \%$ dropout rate, which might limit generalization to all secondary schoolgoing adolescents in Kota Tinggi, Johor. Lastly, the result of the study could only be generalised to secondary school going adolescents in this locality. Thereupon, more longitudinal studies should be carried out in other sites in Malaysia which portrayed more diversity in social and demographic compositions.

\section{Conflict of interest}

The authors declare no potential conflict of interest.

\section{Acknowledgements}

We thank the Director-General of Health Malaysia for his permission topublish this article.

\section{REFERENCES}

1. U.S. Department of Health and Human Services. The health consequences of smoking-50 years of progress: A report of the Surgeon General. Atlanta, GA: U.S. Department of Health and Human Services, Centers for Disease Control and Prevention, National Center for Chronic Disease Prevention and Health Promotion, Office on Smoking and Health U.S. Department of Health and Human Services 2014. 
2. Institute of Public Health, Ministry of Health Malaysia. The report on adults smoking in Malaysia 2015.

3. U.S. Department of Health and Human Services. Preventing Tobacco Use Among Youth and Young Adults: A Report of the Surgeon General. Atlanta, GA: U.S. Department of Health and HumanServices, Centers for Disease Control and Prevention, National Center for Chronic Disease Preventionand Health Promotion, Office on Smoking and Health 2012.

4. Park SH. Smoking and adolescent health. Korean J Pediatr 2011; 54(10):401404. doi:10.3345/kjp.2011.54.10.401

5. World Health Organization. Smokeless Tobacco and Some Tobacco-Specific NNitrosamines. International Agency for Research on Cancer Monographs on the Evaluation of Carcinogenic Risks to Humans Vol. 89. Lyon, (France): World Health Organization, International Agency for Research on Cancer, 2007 [cited 2020 May 8].

6. United States Department of Health and Human Services (USDHHS) 2017. Preventing Tobacco Use Among Youths, Surgeon General factsheet. [cited 2020 May 5]. Available from: https: / /www.hhs.gov/surgeongeneral/rep orts-and-publications/tobacco/preventingyouth-tobacco-use-factsheet/index.html

7. Ministry of Health, Malaysia. National Strategic plan on tobacco control 20152020. Ministry of Health, Malaysia 2014.

8. Bandura A. Social learning theory. New Jersey: Prentice-Hall Inc 1977.

9. Bandura A. Social cognitive theory. In: Vasta R, eds. Annals of child development. Greenwich: JAl Press 1989:1-60.

10. Kandel DB, Griesler PC, $\mathrm{Hu}$ MC. Intergenerational patterns of smoking and nicotine dependence among US adolescents. Am J Public Health 2015;105(11):e63-72.

11. Harakeh Z, Scholte RH, Vermulst AA, De Vries $H$, Engels RC. The relations between parents' smoking, general parenting, parental smoking communication, and adolescents' smoking. J Research on Adolescence 2010 Mar; 20(1):140-65. https: / /doi.org/10.1111/j.1532-

7795.009.00626.x.
12. Mercken L, Sleddens EF, De Vries H, Steglich CE. Choosing adolescent smokers as friends: The role of parenting and parental smoking. J Adoles 2013 Apr 1; 36(2):383-92.

13. Vitória $P$, Pereira SE, Muinos $G$, De Vries $H$, Lima ML. Parents modelling, peer influence and peer selection impact on adolescent smoking behavior: a longitudinal study in two age cohorts. Addict Behav 2020 Jan 1; 100:106-131.

14. Leonardi-Bee J, Jere ML, Britton J. Exposure to parental and siblingsmoking and the risk of smoking uptake in childhood and adolescence: a systematicreview and meta-analysis. Thorax, 2011 Oct 1; 66(10): 849-855.

15. Defoe IN, Semon Dubas J, Somerville LH, Lugtig $P$, van Aken MA. The unique roles of intrapersonal and social factors in adolescent smoking development. Dev Psychol 2016 Dec; 52(12):2044-2056.

16. Lim HL, Heng PP, Sumarni MG, Kee CC, Cheah YK, Lim KH, Lim JH. Prevalence of Smoking and Its Associated Risk Factors Among Secondary School Students in Kelantan, Malaysia. Malaysia Journal of Medicine and Health Sciences 2020; 16(1):44-50.

17. Lim KH, Lim HL, Teh $\mathrm{CH}$, Kee CC, Khoo YY,Subash Shander G, Jane Ling MY, Sumarni MG, Tee EO. Smoking among school-going adolescents in selected secondary schools in Peninsular Malaysiafindings from the Malaysian Adolescent Health Risk Behaviour (MyaHRB) study. Tob Induc Dis 2017; 15(1):1-8.

18. Lim KH, Amal NM, Hanjeet K. Yusof M, Wan Rozita WM, Sumarni MG, Hadzrik NO. Prevalence and factors related to smoking among secondary school students in Kota Tinggi District, Johor, Malaysia. Trop Biomed 2006; 23(1): 75-84.

19. Santrock JW. Adolescence. Boston: McGraw-Hill 2005.

20. Newman BM, Newman PR. Theories of Human Development. New York: Psychology Press 2015.

21. Naing NN, Ahmad Z, Musa R, Hamid FR, Ghazali H, Bakar MH. Factors related to smoking habits of male adolescents. Tob Induced Dis 2004 Sep; 2(3):1-8. doi: 10.1186/1617-9625-2-3-133

22. Shamsuddin K, Haris MA. Family influence on current smoking habits among secondary 
school children in Kota Bharu, Kelantan. Singapore Med J. 2000 Apr 1; 41(4):167-171

23. Hanjeet K., Wan Rozita, W.M. Amal, NM. Risk factors of smoking among secondary school adolescents in Kuala Lumpur. Int Med Res J 2001; 5(2): 59-63.

24. Vitoria PD, Kremers SP, Mudde AN, PaisClemente $M$, de Vries $H$. Psychosocial factors related with smoking behaviour in Portuguese adolescents. European J Can Prev 2006 Dec 1; 15(6):531-40.

25. Wellman RJ, Dugas EN, Dutczak $H$, O'Loughlin EK, Datta GD, Lauzon B, O'Loughlin J. Predictors of the onset of cigarette smoking: a systematic review of longitudinal population-based studies in youth. Am J Prev Med 2016 Nov 1; 51(5):767-78.

26. Liu J, Zhao S, Chen X, Falk E, Albarracín D. The influence of peer behavior as a function of social and cultural closeness: A metaanalysis of normative influence on adolescent smoking initiation and continuation. Psychol Bull 2017 Oct; 143(10):1082. doi:10.1037/bul0000113

27. McKelvey K, Attonito J, Madhivanan P, Yi Q, Mzayek F, Maziak W. Determinants of cigarette smoking initiation in Jordanian schoolchildren: longitudinal analysis. Nicotine Tob Res 2014 Aug 20; 17(5):552-8.

28. Bidstrup $P E$, Frederiksen $K$, Siersma $V$, Mortensen EL, Ross L, Vinther-Larsen M, Grønbæk M, Johansen C. Social-cognitive and school factors in initiation of smoking among adolescents: A prospective cohort study. Cancer Epidemiol Biomarkers Prev2009 Feb 1; 18(2):384-92.

29. Hiemstra $M$, Otten $\mathrm{R}$, de Leeuw $\mathrm{RN}$, van Schayck OC, Engels RC. The changing role of self-efficacy in adolescent smoking initiation. J Adolesc Health 2011 Jun 1; 48(6):597-603.

30. Mahabee-Gittens EM, Khoury JC, Huang B, Dorn LD, Ammerman RT, Gordon JS. The Protective Influence of Family Bonding on Smoking Initiation in Adolescents by Racial/Ethnic and Age Subgroups. J Child Adolesc Subst Abuse 2011 Jul; 20(3):270287. doi: 10.1080/1067828X.2011.581969.

31. Csala I, Elemery M, Martinovszky F, Dome $P$, Dome B, Faludi G, Sandor I, Gyorffy Z,
Birkas E, Lazary J. Maternal bonding styles in smokers and non-smokers: a comparative study. Ann Gen Psychiatry 2016 Nov 11; 15:32. doi: 10.1186/s12991-016-0118-y.

32. Chen J, Ho SY, Wang MP, Lam TH. Parental smoking, rejection of parental smoking, and smoking susceptibility and behaviors in Hong Kong adolescents. Addict Behav 2018 Jul; 82:19-22. doi: 10.1016/j.addbeh.2018.02.019.

33. Mays D, Gilman SE, Rende R, Luta G, Tercyak KP, Niaura RS. Parental smoking exposure and adolescent smoking trajectories. Pediatrics 2014 Jun; 133(6):983-91. doi: 10.1542/peds.2013-3003.

34. Gilman SE, Rende R, Boergers J, et al. Parental smoking and adolescent smoking initiation: an intergenerational perspective on tobacco control. Pediatrics. 2009 Feb; 123(2):e274-81. doi: 10.1542/peds.20082251.

35. Wen CP, Tsai SP, Cheng TY, Hsu CC, Chen $\mathrm{T}$, Lin HS. Role of parents and peers in influencing the smoking status of high school students in Taiwan. Tob Control 2005 Jun; 14(Suppl 1):i10-5. doi: $10.1136 /$ tc. 2003.005637 .

36. Kodl MM, Mermelstein R. Beyond modeling: parenting practices, parental smoking history, and adolescent cigarette smoking. Addict Behav2004 Jan; 29(1):17-32. doi: 10.1016/s0306-4603(03)00087-x.

37. Chassin L, Presson C, Seo DC, Sherman SJ, Macy J, Wirth RJ, Curran P. Multiple trajectories of cigarette smoking and the intergenerational transmission of smoking: a multigenerational, longitudinal study of a Midwestern community sample. Health Psychol 2008 Nov; 27(6):819-28. doi: 10.1037/0278-6133.27.6.819.

38. Flay BR, Hu FB, Siddiqui O, Day LE, Hedeker $D$, Petraitis J, Richardson J, Sussman S. Differential influence of parental smoking and friends' smoking on adolescent initiation and escalation of smoking. $J$ Health Soc Behav. 1994 Sep; 35(3):248-65.

39. Lim HL, Teh CH, Kee CC, Normala I, Lim KH. Do adolescents under-report their smoking status? - Findings from secondary school students in Kota Tinggi, Johor. Int. J Pub Health and Clic Sci 2017 Apr 17; 4(2):66-72. 